\title{
Acoustic Emission Characterization of Matrix Damage Initiation in Woven CFRP Composites
}

\author{
Mostefa Bourchak $^{1^{*}}$, Adnan Khan ${ }^{1}$, Salah A. Badr ${ }^{2}$, Wail Harasani ${ }^{1}$ \\ ${ }^{1}$ Aeronautical Engineering Department, King Abdulaziz University, Jeddah, Saudi Arabia; ${ }^{2}$ Mining Engineering Department, King \\ Abdulaziz University, Jeddah, Saudi Arabia. \\ Email: *mbourchak@kau.edu.sa
}

Received June $25^{\text {th }}, 2013$; revised July $27^{\text {th }}, 2013$; accepted August $6^{\text {th }}, 2013$

Copyright (C) 2013 Mostefa Bourchak et al. This is an open access article distributed under the Creative Commons Attribution License, which permits unrestricted use, distribution, and reproduction in any medium, provided the original work is properly cited.

\begin{abstract}
In this paper, an experimental investigation is performed using acoustic emission (AE) technique to study the behaviour of crack initiation and propagation of woven carbon fibre reinforced plastic (CFRP) composites under static tensile loading. Three laminates with three plies each were manufactured and tested under tensile static loading. Damage was being monitored using AE technique with instantaneous AE hits energies being used as the damage parameter. Results showed that angle ply laminates experienced crack initiations at about $50 \%$ of ultimate tensile strength whereas cross ply laminates and non-conventional angle ply laminates having one cross ply laminate experienced initiation of cracks at about a third of ultimate tensile strength. This early cracks initiation is believed to be caused by the presence of $90^{\circ}$ plies that cannot take much load transversely.
\end{abstract}

Keywords: CRFP; Ply Angle Effect; Static Tensile Test; Acoustic Emission; Crack Initiation

\section{Introduction}

The initiation and propagation of the failure modes in CFRP laminates under mechanical loads is usually difficult to predict and monitor. One of the principle reasons for that is the lack of transparency of CFRP composites that does not allow the inner damage evaluation by common inspection methods. For this reason, AE technique is used on composite materials to characterize damage failure modes under various loading conditions.

AE technique is one of the principle NDT methods for distinguishing and identifying growing material defects [1]. AE is defined according to ASTM standard [2] as "the class of phenomena where transient elastic waves are generated by the rapid release of energy from localized sources within a material, or the transient elastic waves so generated". In context of fibre reinforced composites, the $\mathrm{AE}$ waves are stress waves generated by the mechanical deformation of materials e.g., initiation/ growth of cracks, yielding, material dislocations, impacts, rubbing of contacting surfaces and fibre failure [3]. Typically, mechanical stresses are produced by applying external forces causing the release of elastic energy "waves", e.g. by crack formation. The elastic wave

"Corresponding author. propagating through the material is detected and converted into an electrical AE signal by the AE sensors. The AE system processes the AE signal, converts the received wave packets into feature data sets, determines the source location, calculates statistics, and displays them graphically and numerically. AE systems contain parametric channels to measure the environmental conditions as well as the external load as reference parameters for the detected AE hits [4].

Many researchers studied the influence of various parameters, such as fibre orientation, laminate thickness and stacking sequence on the acoustic waves response, often analysing signal count, amplitude and energy [5-7]. AE technique was found to demonstrate excellent results on detecting and identifying initiations sites, cracking propagation and failure mechanisms of CFRP composite. Moreover, the use of AE is not only limited to study the initiation of cracks and its wave propagation in CFRP composites but also in natural fibre reinforced composite materials [8]. In particular, AE is used to determine the strength of the interface between fibres and polymer matrices. Additionally, AE is also successfully used to monitor damage in other materials such as metals [9]. Hufenbach et al. [10] carried out an experiment with differently structured multi-layered symmetric cross-ply 
and angle-ply laminates, for different textile fabrics. They found out that failure of a thermosetting and thermoplastic fibrous composite could be forecasted far before the real total failure by a strongly exponential increase of the AE activity. Their findings were in agreement with Bourchak et al. [7] results regarding crack initiation and failure threshold observed in CFRP composites with the use of $\mathrm{AE}$ technique. Lopresto et al. [11] executed an experiment in which extensional mode of propagation was analysed. The data collected were used to find the four elastic constants characterizing the inplane behaviour of the basic lamina. Whereas, Liu et al. [12] tested epoxy composite specimens used AE technique to study the effects of different lay-up patterns and mapping between the failure properties and the acoustic signal features. It was expected that the influence of complex lay-up patterns and sizes on the damage and failure properties of composites be represented by creating true mapping based on the $\mathrm{AE}$ technique. Mizutani et al. [13] used AE signal in combination with the modal analysis of lamb waves. The sequence of microscopic fracture mechanisms in locally loaded cross-ply carbon fibre composites were studied using microscopic and ultrasonic examination.

Some researchers have used numerical model method to validate the results with the $\mathrm{AE}$ data. Johnson and Gudmunson [14] studied the transient wave propagation resulting from transverse matrix cracking in cross ply composite tensile test specimens that were investigated both theoretically and experimentally. The comparisons indicated a close resemblance between experimentally measured and numerically calculated signals. May et al. [15] carried out a series of tests which were conducted to act as validation cases for the numerical model to predict the initiation and propagation of damage in composite materials. The number of cracks identified by significant AE hits correlated well with the number of cracks identified by X-rays. Truong et al. [16] investigated the initiation of damage in laminates due to tensile loading using acoustic emission and X-ray radiography. The damage initiation and evolution in the composites reinforced with sheared fabrics depends on the shear angle of the reinforcement. Kam and Lai [17] carried out experimental and theoretical methods to study the first ply failure strength of laminated composite plates under different loading conditions. A finite element analysis, which was constructed based on the layer wise linear displacement theory and the Tsai $\mathrm{Wu}$ failure criterion, were used to predict the first ply failure strength of the plates. Havaldar et al. [18] examined the influence of architecture on the compressive behaviour of angle-ply composite laminates using dynamic load. The analytic predictions and experimental results both showed that the biaxial stress state that develops in angle-ply composite laminates has a significant effect on the axial compressive strength. Lopresto et al. [19] used AE to investigate the influence of the stacking sequence and direction on the acoustic response of the materials and suggested that a method based on attenuation, rather than arrival time, could be useful for source location in composite laminates.

Furthermore, angle ply composite laminates are an important class of laminates because they combine good properties in both axial and shear directions. Several investigators have evaluated the use of angle-ply laminates to determine compressive strength. Moreover, the properties of the composite with different angel ply can be found by the classical laminate analysis method, but in this paper we aim to study the crack initiation and propagation of $\mathrm{AE}$ waves which makes the effect of altering ply angle more distinctive. As part of this work, static tensile tests with $\mathrm{AE}$ technique are performed on woven CFRP composite laminates with different lay-up pattern to study the damage initiation and propagation. Some representative features such as the AE signals energy are extracted with the load to study the initiation of cracks and their propagation up to ultimate failure. The stress at which Acoustic Emission activity starts is referred here as the crack initiation stress. Ultimate tensile stress is the stress at total specimen failure. One of the objectives of this work is to shed light on any possible relationship between these two stresses.

\section{Experimental Setup}

\subsection{Specimens Preparation}

The specimens were prepared using T300 plain 2D weave carbon fibre shown in Figure 1 and Epolam 2063 two-component epoxy resin. The Epolam 2063 epoxy resin has a low viscosity and a high reactivity. It also has long gel time and behaves well in damp environment. The formulated resin should yield good mechanical, electrical, chemical and water resistance properties. The Epolam 2063 provide excellent characteristics when used as poly epoxy resins. Successful applications include large filament wound booster and missile motor cases, pressure vessels, composite pipes, reverse osmosis tubular high pressure equipment, aerospace and automotive components and high temperature epoxy tooling, etc. The Epolam pre-mix ratio of resin to hardener is 48:52.

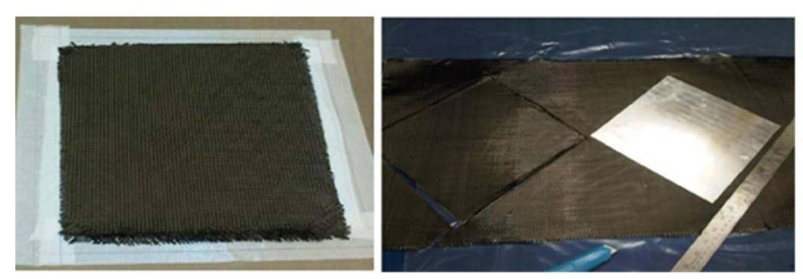

Figure 1. T300 2D weave woven fabric used for laminates manufacturing. 
The resulting matrix was mixed well using a magnetic stirrer shown in Figure 2. Three different batches of specimens were then prepared using resin infusion method as shown in Figure 3. The laminates were cured in a hot press using the manufacturer's recommended curing cycle. The latter consisted of three stages; preheating at $80^{\circ} \mathrm{C}$ for 30 minutes, curing for six hours at $80^{\circ} \mathrm{C}$ and then post curing for four hours at $80^{\circ} \mathrm{C}$. After the curing, average thicknesses were found to be approximately 0.6 $\mathrm{mm}$ for all three laminate.

Four specimens were cut from each laminate according to ASTM standard [20] using a diamond saw machine. The specimens were $20 \mathrm{~mm}$ wide and had a gauge length of $100 \mathrm{~mm}$. The specimens are shown in Figure 4 (after testing) and have the following layups:

1) Laminate A specimens layup: $\left( \pm 45^{\circ}\right)_{3}$.

2) Laminate $B$ specimens layup: $\left(0^{\circ} / 90^{\circ}\right)_{3}$.

3) Laminate $C$ layup: $\left[\left(0^{\circ} / 90^{\circ}\right),\left(-30^{\circ}, 60^{\circ}\right),\left(30^{\circ},-60^{\circ}\right)\right]$.

\subsection{AE Damage Detection System}

Static tensile tests were then performed as per ASTM standard [20] using a MTS 809 testing machine at a crosshead speed of $2 \mathrm{~mm} / \mathrm{min}$. The data was analysed to examine the initiation of cracks stress levels and how this stress threshold is affected by altering the plies angles.

Damage was being monitored using Vallen AMSY-5 AE system seen in Figure 5. The AE equipment is composed of the transducers, the preliminary amplifiers and software for signal gathering and processing, recording and display as shown in Figure 5.

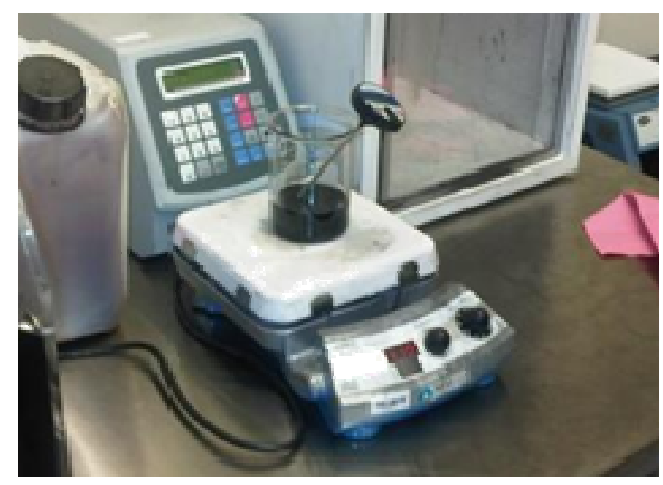

Figure 2. Matrix mixing using magnetic stirrer.

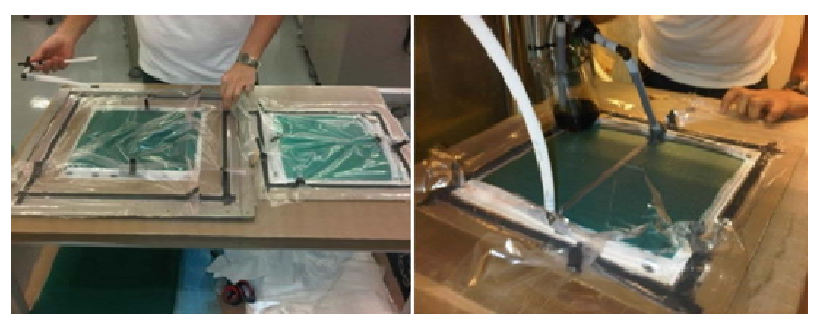

Figure 3. Laminate preparation using resin infusion technique.
Considering the stress sensitivity for composite laminates, two $\mathrm{AE}$ transducers (sensors) are symmetrically placed on the specimen ends $85 \mathrm{~mm}$ apart and slightly away from the machine grips as shown in Figure 6.

The difference in the arrival time of the AE signals received by these two transducers is used to find the source locations of damage events. The preliminary amplifier employs the enlarging circuits with a wide frequency. The signal gathering and processing systems describe the energy time curve, the counting time curve and the amplitude time curve. To improve the test precision, the sensitivity and consistency of the AE system are calibrated before experiments. A $0.5 \mathrm{~mm}$ pencil lead break tests were carried out prior to each test to calibrate the hits location accuracy of the AE system as per ASTM standard [21]. The pencil lead was broken against the CFRP laminates and the produced elastic waves are recorded by two transducers and its results analysed to work out the speed of sound on the laminate.

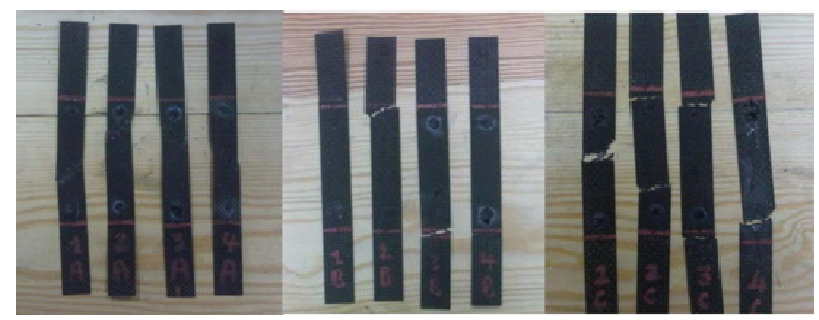

Figure 4. Tested specimens (Laminate (a) left, Laminate (b) centre and Laminate (c) right).

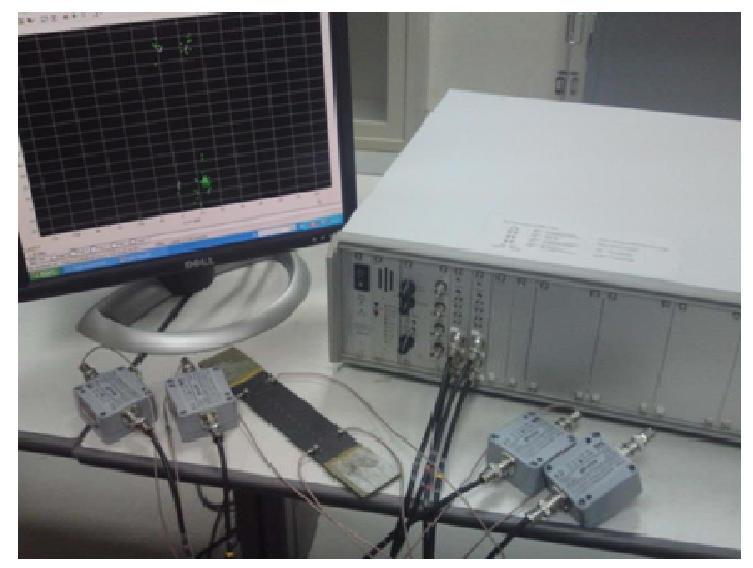

Figure 5. Vallen AMSY-5 AE System.

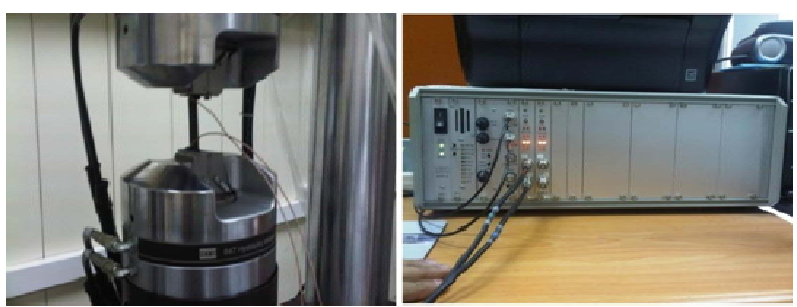

Figure 6. Composite specimen positioned for AE test. 


\section{Results and Discussion}

Figures 7-9 show the AE energy vs. tensile stress for all laminates $\mathrm{A}, \mathrm{B}$ and $\mathrm{C}$ specimens respectively. It can be seen clearly how AE energy fluctuates whenever there is damage happening on the specimen up to final failure. However, for the objective of this work, only the stress level at the point of crack initiation is of importance. All figures show a distinct behaviour where no AE activity is recorded earlier in the loading curve until the matrix cracks in the specimens start to occur. After that, there are different peaks of AE energy that represent the severity of damage where fibre breaks usually cause the highest energy levels $[7,22,23]$. It is also noticed that AE energy activity slows down indicating saturation in the laminate damage towards ultimate failure. Most of the AE activity and consequently early damage is contrib.uted to the presence of off-axis (i.e., off loading axis) plies.

Data extracted from Figures 7-9 are summarized in Tables 1-3 for laminates A, B and $\mathrm{C}$ respectively. These tables show the tensile tests results for all tested specimens in terms of average stress levels at which matrix cracks initiated and also the ultimate tensile stress. Even though fibre reinforced composite materials are known to have significant statistical scatter in mechanical test data due to the complex interaction between fibres and resin as well as the uncontrollable manufacturing variations [24], the results of this work were consistent from speci-
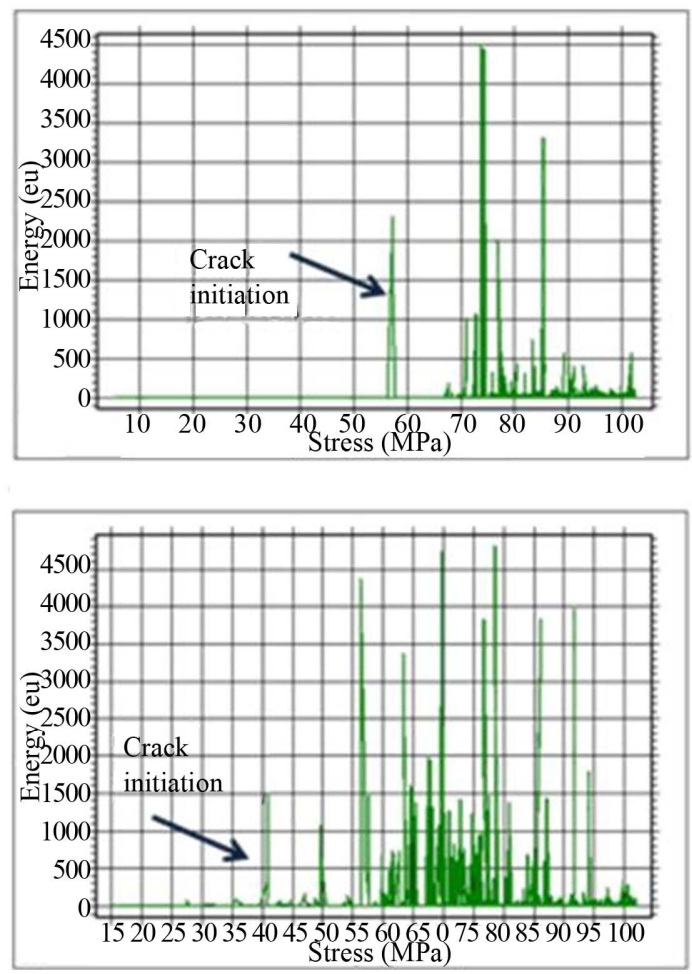

men to specimen as shown in Tables 1-3.

Figure 10 shows a summary of results. As can be seen, the matrix crack initiation stress is almost half $(55 \%)$ the ultimate stress in the $\left( \pm 45^{\circ}\right)_{3}$ angle ply specimens whereas it is about a third $(32 \%)$ of ultimate tensile stress in the $\left(0^{\circ} / 90^{\circ}\right)_{3}$ cross ply specimens and also about a third $(36 \%)$ of ultimate tensile stress in the unconventional angle ply laminate $\mathrm{C}$. Unlike Laminate A specimens, the similarities in matrix crack initiation stress level in laminates $\mathrm{B}$ and $\mathrm{C}$ are contributed to the presence of $90^{\circ}$ fibres. It is also noticed how the strength of angle ply specimens is significantly reduced by using only $\left( \pm 45^{\circ}\right)$ plies.

\section{Conclusions}

Changing ply angles in CFRP composites is known to significantly affect the ultimate tensile strength. However, the presence of $90^{\circ}$ plies can cause the matrix to crack early and at a similar stress level regardless of the presence of other non $90^{\circ}$ plies. However, to detect this important threshold is necessary to use a sensitive damage detection method such as AE technique. Additionally, this damage threshold is found to be as little as a third of the ultimate tensile strength in woven CFRP composite laminates having some of its fibres laying on the $90^{\circ}$ angle. Consequently, results of this work indicate that in woven CFRP composite laminates there is a nonlinear relationship between fibre angle, ultimate tensile strength and matrix crack initiation stress level.
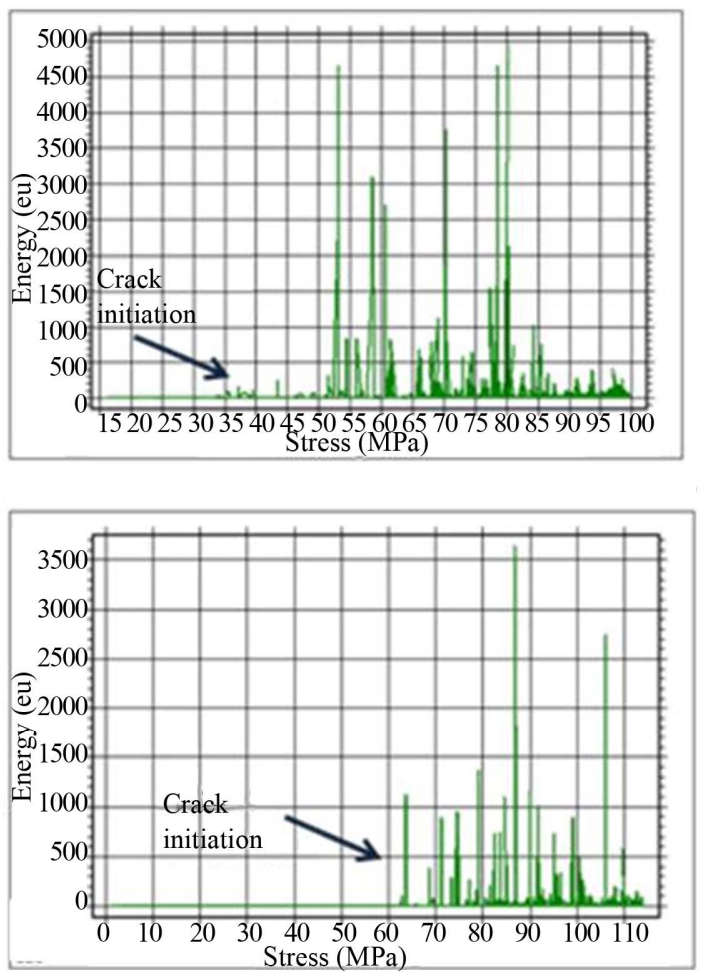

Figure 7. Crack initiation stress in Batch $\left( \pm 45^{\circ}\right)_{3}$ laminates. 

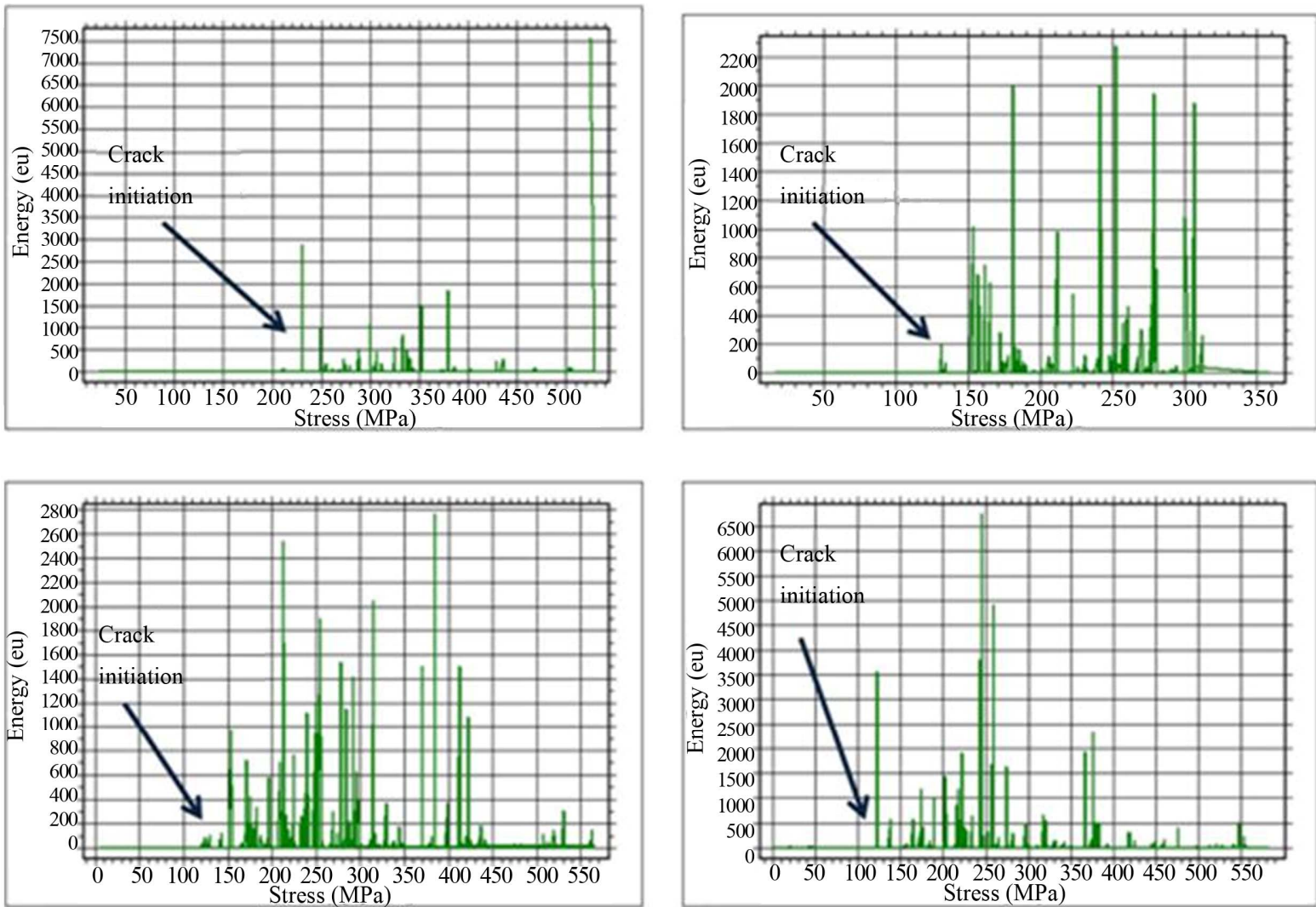

Figure 8. Crack initiation stress in Batch $\left(0^{\circ} / 90^{\circ}\right)_{3}$ laminates.
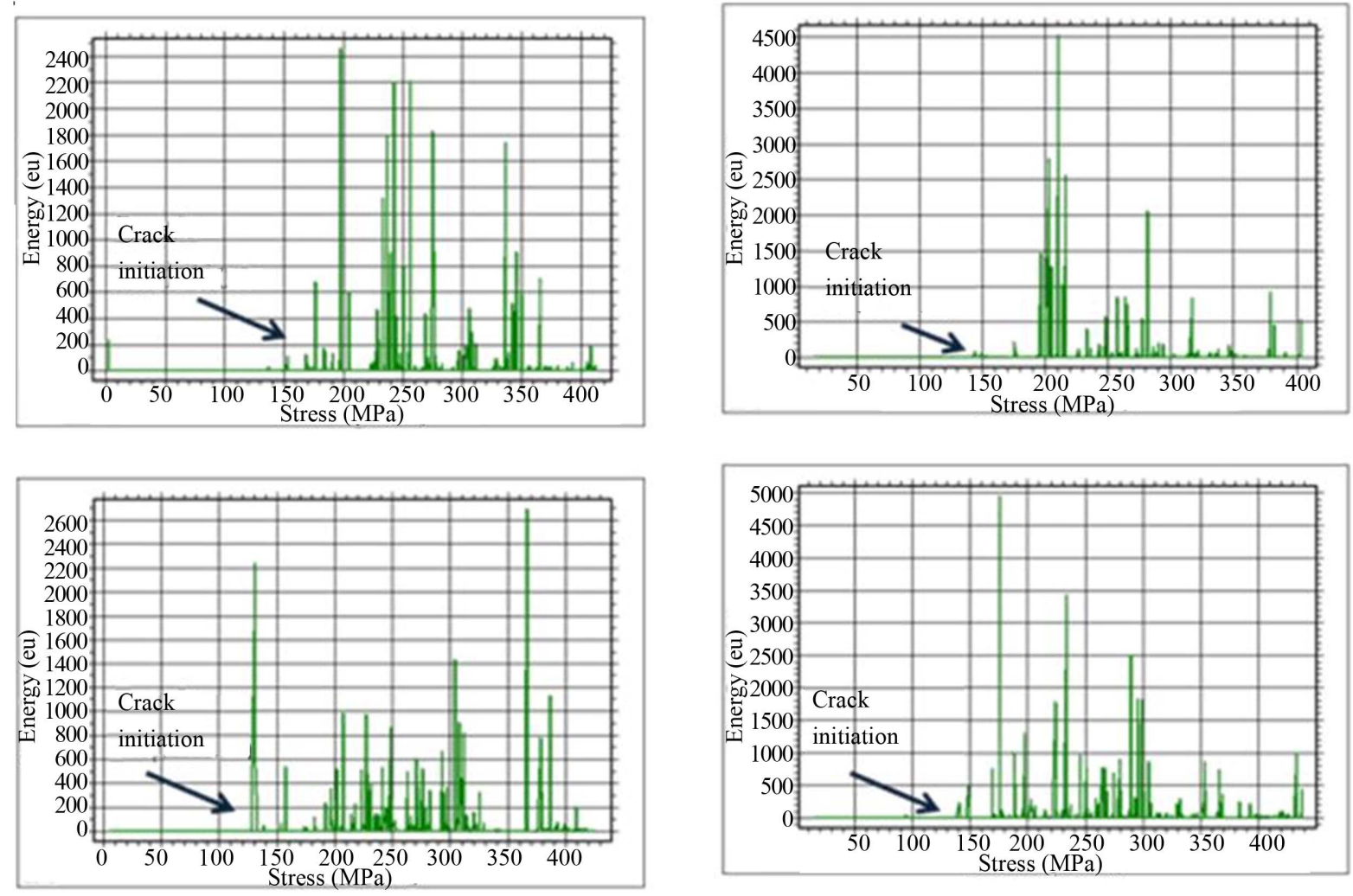

Figure 9. Crack initiation stress in Batch $\left(0^{\circ} / 90^{\circ},-30^{\circ} / 60^{\circ}, 30^{\circ} /-60^{\circ}\right)$ laminates. 


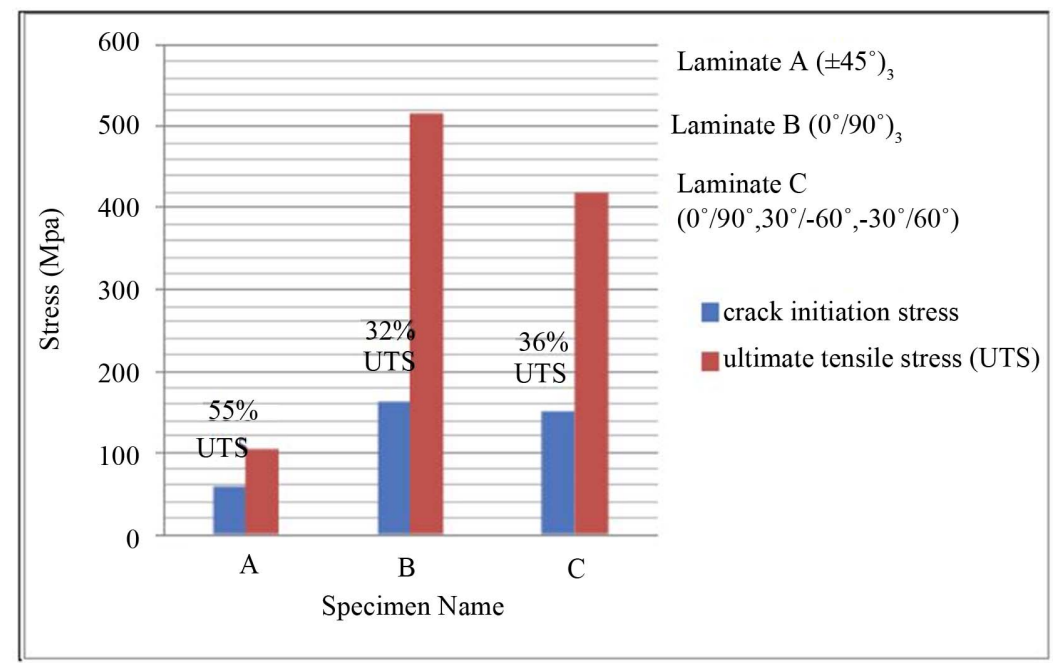

Figure 10. Summary of ratios of crack initiation stress to ultimate tensile stress.

Table 1. Crack initiation and ultimate stresses in angle ply specimens $\left( \pm 45^{\circ}\right)_{3}$.

\begin{tabular}{ccc}
\hline \multicolumn{3}{c}{ Specimen A } \\
\hline Specimen & Crack initiation stress (MPa) & Ultimate Stress (MPa) \\
\hline A1 & 58 & 103 \\
A2 & 53 & 100 \\
A3 & 41 & 102 \\
A4 & 63 & 113 \\
Average & 57.53 & 104.5 \\
\hline
\end{tabular}

Table 2. Crack initiation and ultimate stresses in angle ply specimens $\left(0^{\circ} / 90^{\circ}\right)_{3}$.

\begin{tabular}{ccc}
\hline \multicolumn{3}{c}{ Specimen B } \\
\hline Specimen & Crack initiation stress (MPa) & Ultimate Stress (MPa) \\
\hline B1 & 230 & 530 \\
B2 & 150 & 383 \\
B3 & 150 & 565 \\
B4 & 120 & 585 \\
Average & 162.5 & 515.75 \\
\hline
\end{tabular}

Table 3. Crack initiation and ultimate stresses in angle ply specimens $\left[\left(0^{\circ} / 90^{\circ}\right),\left(-30^{\circ} / 60^{\circ}\right),\left(30^{\circ} /-60^{\circ}\right)\right]$.

\begin{tabular}{ccc}
\hline \multicolumn{3}{c}{ Specimen C } \\
\hline Specimen & Crack initiation stress (MPa) & Ultimate Stress (MPa) \\
\hline C1 & 150 & 410 \\
C2 & 175 & 405 \\
C3 & 130 & 425 \\
C4 & 150 & 438 \\
Average & 151.25 & 419.5 \\
\hline
\end{tabular}

Moreover, this work focused specifically on the general alteration of ply angles and how this affect the crack initiation stress with some sequences chosen for experimental investigation. However, due to the nature of composite materials, vast amount of possible stacking sequences could be designed. A more precise investigation is recommended to make the relationship between crack initiation stress and ultimate tensile stress more generic regardless of the stacking sequence. This can only be done with a comprehensive tests program that includes a large number of specimens.

\section{REFERENCES}

[1] R. K. Miller and P. McIntire, "Nondestructive Testing Handbook; v.5," American Society for Nondestructive Testing, Inc., 1987

[2] International ASTM Standard, "Test Method for Examination of Seamless, Gas Filled, Pressure Vessels Using Acoustic Emission,” E1419-09.

[3] M. R. Kaphle and A. Tan, "Source Location of Acoustic Emission Waves for Structural Health Monitoring of Bridges," In: J. Sumeet and L. Wang, Eds., Infrastructure Research Theme Postgraduate Student Conference 2009: Rethinking Sustainable Development: Planning, Engineering, Design and Managing Urban Infrastructure, 26 March 2009, Brisbane.

[4] A. A. Pollock, "Acoustic Emission Inspection, Metals handbook," ASM International, Vol. 17, 1989, pp. 278294.

[5] M. Wevers and M. Surgeon, "Acoustic Emission and Composites," Comprehensive Composite Materials, Vol. 5, No. 1, 2000, pp. 345-357. doi:10.1016/B0-08-042993-9/00079-6

[6] V. Lopresto, C. Leone, G. Caprino and I. de Iorio, "Composite Materials Characterization by Acoustic Emission Technique," Department of Materials and Production Engineering, University of Naples "Federico II", 
Vol. 1, No. 1, 2011, pp. 1-2.

[7] M. Bourchak, I. R. Farrow, I. P. Bond, C. W. Rowland and F. Menan, "Acoustic Emission Energy as a Fatigue Damage Parameter for CFRP Composites," International Journal of Fatigue, Vol. 29, No. 3, 2007, pp. 457-470. doi:10.1016/j.ijfatigue.2006.05.009

[8] I. M. De Rosa, C. Santulli and F. Sarasini, "Acoustic Emission for Monitoring the Mechanical Behaviour of Natural Fibre Composites: A Literature Review," Journal of Composites: Part A, Vol. 40, No. 1, 2009, pp. 14561469. doi:10.1016/j.compositesa.2009.04.030

[9] T. M. Roberts and M. Talebzadeh, "Acoustic Emission Monitoring of Fatigue Crack Propagation," Journal of Constructional Steel Research, Vol. 59, No. 1, 2003, pp. 695-712. doi:10.1016/S0143-974X(02)00064-0

[10] W. Hufenbach, H. Richter, A. Langkamp and R. Böhm, "Application of Acoustic Emission Analysis for Damage Investigations in Fibre and Textile Reinforced Composites," TU Dresden, Institute of Lightweight Structures and Polymer Technology, Vol. 1, No. 1, 2001, pp. 1-10.

[11] V. Lopresto, C. Leone, G. Caprino and I. de Iorio, "Analysis of Acoustic Emission Signals Produced by Different CFRP Laminates," ICCM-17, Vol. 1, No. 1, 2011, pp. $1-10$.

[12] P. F. Liu, J. K. Chu, Y. L. Liu and J. Y. Zheng, "A Study on the Failure Mechanisms of Carbon Fibre/Epoxy Composite Laminates Using Acoustic Emission," Journal of Materials and Design, Vol. 37, No. 1, 2011, pp. 228235.

[13] Y. Mizutani, K. Nagashima, M. Takemoto, K. Ono, "Fracture Mechanism Characterization of Cross-Ply Carbon-Fibre Composites Using Acoustic Emission Analysis," Journal of NDT\&E International, Vol. 33, No. 1, 2000, pp. 101-110. doi:10.1016/S0963-8695(99)00030-4

[14] M. Johnson and P. Gudmundson, "Experimental and Theoretical Characterization of Acoustic Emission Transients in Composite Laminates," Journal of Composites Science and Technology, Vol. 61, No. 1, 2001, pp. 13671378. doi:10.1016/S0266-3538(01)00036-7

[15] M. May, R. Pullin, M. Eaton, C. Featherston and S. R. Hallett, "An Advanced Model for Initiation and Propagation of Damage Under Fatigue Loading - part II: Matrix Cracking Validation Cases," Journal of Composite Struc- tures, Vol. 93, No. 1, 2011, pp. 2350-2357. doi:10.1016/j.compstruct.2011.03.023

[16] T. C. Truong, D. S. Ivanov, D. V. Klimshin, S. V. Lomov and I. Verpoest, "Carbon Composites Based on MultiAxial Multi-Ply Stitched Preforms. Part 7: Mechanical Properties and Damage Observations in Composites with Sheared Reinforcement," Journal of Composites: Part A, Vol. 39, No. 1, 2008, pp. 1380-1393. doi:10.1016/i.compositesa.2008.05.004

[17] T. Y. Kam and F. M. Lai, "Experimental and Theoretical Predictions of First Ply Failure Strength of Laminated Composite Plates," International Journal of Solids and Structures, Vol. 36, No. 1, 1998, pp. 2379-2395.

[18] S. Havaldar, R. Sharma, S. Jain, R. Kumar, A. Jaiswal, "Effects of Angle Ply Orientation on Dynamic Characteristics of Composite Laminates," International Journal of Advanced Engineering \& Application, Vol. 2, No. 1, 2011, pp. 120-122.

[19] V. Lopresto, C. Leone, G. Caprino, I. de Iorio and I. Papa, "Thick Layer Equally Oriented Effect on Acoustic Emission Behaviour of Carbon Fibre Reinforced Plastic Laminates," Department of Materials and Production Engineering, University of Naples "Federico II," Vol. 1, No. 1, 2011, pp. 1-5.

[20] International ASTM Standard, "Test Method for Tensile Properties of Polymer Matrix Composite Materials," D3039/D3039M-08.

[21] International ASTM Standard, "Hsu-Nielsen, Pencil lead break AE test," E976-94.

[22] J. M. Berthelot and J. Razi, "Acoustic Emission in Carbon Fibre Composites," Composites Science and Technology, Vol. 37, No. 4, 1990, pp. 411-428. doi:10.1016/0266-3538(90)90012-T

[23] H. D. Yun, W. C. Choi and S. Y. Seo, "Acoustic Emission Activities and Damage Evaluation of Reinforced Concrete Beams Strengthened with CFRP Sheets," NDT and E International, Vol. 43, No. 7, 2010, pp. 615-628. doi:10.1016/j.ndteint.2010.06.006

[24] H. Hamada, N. Oya, K. Yamashita and Z. I. Maekawa, "Tensile Strength and Its Scatter of Unidirectional Carbon Fibre Reinforced Composites," Journal of Reinforced Plastics and Composites, Vol. 16, No. 2, 1997, p. 119. 